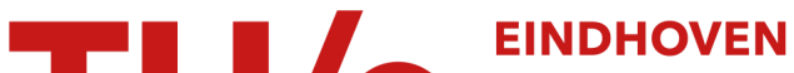 UNIVERSITY OF TECHNOLOGY
}

\section{Chemical mapping of silica prepared via Sol-Gel reaction in rubber nanocomposites}

Citation for published version (APA):

Miloskovska, E., Friedrich, C., Bogaerds - Hristova, D. G., Persenair, O., Duin, van, M., Hansen, M. R., \& With, de, G. (2015). Chemical mapping of silica prepared via Sol-Gel reaction in rubber nanocomposites.

Macromolecules, 48(4), 1093-1103. https://doi.org/10.1021/ma5020929

DOI:

10.1021/ma5020929

Document status and date:

Published: 01/01/2015

Document Version:

Publisher's PDF, also known as Version of Record (includes final page, issue and volume numbers)

Please check the document version of this publication:

- A submitted manuscript is the version of the article upon submission and before peer-review. There can be important differences between the submitted version and the official published version of record. People interested in the research are advised to contact the author for the final version of the publication, or visit the $\mathrm{DOI}$ to the publisher's website.

- The final author version and the galley proof are versions of the publication after peer review.

- The final published version features the final layout of the paper including the volume, issue and page numbers.

Link to publication

\section{General rights}

Copyright and moral rights for the publications made accessible in the public portal are retained by the authors and/or other copyright owners and it is a condition of accessing publications that users recognise and abide by the legal requirements associated with these rights.

- Users may download and print one copy of any publication from the public portal for the purpose of private study or research.

- You may not further distribute the material or use it for any profit-making activity or commercial gain

- You may freely distribute the URL identifying the publication in the public portal.

If the publication is distributed under the terms of Article $25 \mathrm{fa}$ of the Dutch Copyright Act, indicated by the "Taverne" license above, please follow below link for the End User Agreement:

www.tue.nl/taverne

Take down policy

If you believe that this document breaches copyright please contact us at:

openaccess@tue.nl

providing details and we will investigate your claim. 


\title{
Chemical Mapping of Silica Prepared via Sol-Gel Reaction in Rubber Nanocomposites
}

\author{
Elena Miloskovska, ${ }^{*},{ }^{\dagger}{ }^{\dagger}$ Cornelius Friedrichs, $"$ Denka Hristova-Bogaerds, ${ }^{\dagger}$ Olivier Persenair, ${ }^{\#}$ \\ Martin van Duin, ${ }^{\%}$ Michael Ryan Hansen, ${ }^{*}, \|, \perp$ and Gijsbertus de With ${ }^{\ddagger}$
}
${ }^{\dagger}$ Department Chemical Engineering \& Chemistry, Laboratory of Polymer Technology, and ${ }^{\star}$ Department of Chemical Engineering \& Chemistry, Laboratory of Materials and Interface Chemistry, Eindhoven University of Technology, P.O. Box 513, 5600 MB Eindhoven, The Netherlands ${ }^{\S}$ Dutch Polymer Institute (DPI), P.O. Box 902, 5600 AX, Eindhoven, The Netherlands
"Max Planck Institute for Polymer Research, Ackermannweg 10, 55021 Mainz, Germany
${ }^{\perp}$ Interdisciplinar Nanoscience Center (iNANO) and Department of Chemistry, Aarhus University, Gustav Wieds Vej 14, DK-8000 Aarhus C, Denmark
\#Laboratory of Polymeric \& Composite Materials, University of Mons - Umons, Avenue N. Copernic 1, B-7000 Mons, Belgium
${ }^{\%}$ LANXESS Elastomers R\&D, P.O. Box 185, 6160 AD Geleen, The Netherlands

ABSTRACT: Rubber-silica nanocomposites containing $10 \mathrm{wt}$ $\%$ silica were prepared using in situ hydrolysis and condensation of tetraethyl orthosilicate (TEOS) in the presence of $n$ hexylamine as catalyst in two rubber matrices, namely, natural rubber and ethylene-propylene diene rubber. The structure of sol-gel synthesized silica, mapped by solid-state NMR spectroscopy and XPS, indicated the presence of remnant ethoxy groups inside the silica particles and on the silica surface, while hexylamine resided preferentially at the silica surface stabilized via hydrogen bonding of the ethoxy and chemisorption of the

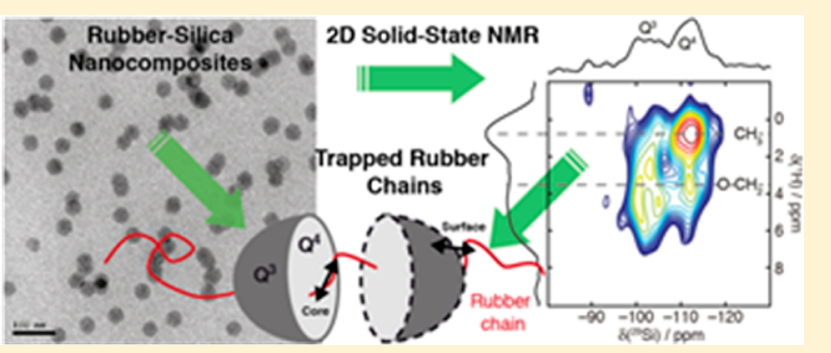
hexylamine. Thus, the preparation of sol-gel synthesized silica results in the formation of so-called "hairy" silica particles with increased hydrophobic properties. The combinatory technique FTIR-TGA-MS confirms the complex chemistry of the sol-gel synthesized silica as well as the low amount of residual ethanol present in the particles and the in situ rubber-silica nanocomposite, the latter aspect being important when industrial manufacturing and application of in situ rubber-silica nanocomposites is considered. It is further shown that (i) the particular surface chemistry, (ii) the phenomena of entrapped rubber chains inside the silica nanoparticles, and (iii) morphology of the sol-gel synthesized silica nanoparticles lead to a more intimate interaction with the rubber matrix, which may be fine-tuned toward improved mechanical properties.

\section{INTRODUCTION}

Commercially available silica, whether precipitated, fumed, or prepared otherwise, is an amorphous material that consists of silicon and oxygen atoms in a tetrahedral arrangement interconnected to form a nonregular three-dimensional network of $\mathrm{Si}-\mathrm{O}-\mathrm{Si}$ bonds with silanol groups $(\mathrm{Si}-\mathrm{OH})$ present inside the structure and on the surface. The chemical composition and the physical characteristics, such as pore size, surface area, density, and silanol content, are largely responsible for the utility of this material in various applications, including catalysis, separation operations, and composite materials. The surface silanol groups are considered to be responsible for the high polarity of silica. ${ }^{1-3}$ Several studies have been conducted using one-dimensional (1D) and two-dimensional (2D) solid-state NMR and FTIR techniques for complete surface mapping of highly dispersible (HD) silica $^{4,5}$ and related systems ${ }^{6}$ in addition to clarifying specific surface interactions. ${ }^{7}$ A similar structure is expected for amorphous silica obtained via the sol-gel process, where, by means of hydrolysis of alkoxysilanes and subsequent condensation of silanol groups, silica particles are produced. ${ }^{8,9}$ One must realize that during the hydrolysis reaction, alkoxysilanes are not always fully hydrolyzed, suggesting that the nonhydrolyzed alkoxy groups can be trapped during the sol-gel reaction inside the silica structure and/or remain on the surface. The presence of residual alkoxy groups for sol-gel synthesized fabricated silica has in fact been reported earlier, ${ }^{10,11}$ indicating a possibly different chemical structure of silica obtained via the sol-gel reaction.

Traditionally, silica is mixed with rubber compounds via several mixing steps in the presence of a coupling agent; i.e., silica is often referred to as a filler material. The coupling agent aims at improving the silica dispersion and, with that, the rubber reinforcement. ${ }^{12-19}$ The in situ rubber-silica nano-

Received: October 13, 2014

Revised: January 15, 2015

Published: January 30, 2015 
composites, reinforced with silica formed via the sol-gel reaction, can show better mechanical properties as compared to conventional nanocomposites obtained via mixing. ${ }^{20-22}$ These in situ rubber-silica nanocomposites typically consist of uniformly distributed, single silica particles, where no silica particle-particle network formation is observed. Recent studies have focused on the structural characterization of rubber-silica reinforced nanocomposites, whereas others have devoted their efforts to understand the changes in mechanical properties using a number of different experimental techniques. ${ }^{23-27} \mathrm{On}$ the basis of these studies, it has been proposed that rubbersilica reinforced nanocomposites may form so-called "trapped entanglements" as a result of temporary bonding of rubber chains to the silica surface. The extent of such rubber-silica interactions strongly depends on the polarity of the rubber, where a more polar rubber will allow a stronger anchoring of the rubber chains to the silica surface. This will most likely result in a larger number of trapped entanglements and, consequently, a larger effect on the overall entanglement density of the rubber matrix. Thus, rubber-silica interactions are considered to be the key parameter for achieving optimal reinforcement in rubber nanocomposites, where several studies $^{28,29}$ have emphasized their importance for a better understanding of rubber reinforcement.

From a structural point of view, the improved rubber-silica interactions assumed to be present in the in situ rubber-silica nanocomposites have been ascribed to the possibility of fewer silanol groups being present on the silica surface, resulting in a lower hydrophilicity of the silica. Up until now only a few studies $^{30-32}$ have suggested-but never proven-that there may indeed be fewer silanol groups on the sol-gel synthesized silica surface. One must also note the importance of the amount of ethanol released during the silanization reaction in the compounding process of the conventional nanocomposites and the sol-gel reaction during preparation of the in situ rubbersilica nanocomposites. In general, the removal of ethanol is difficult because it has tendency to form hydrogen bonds with the silanol groups present on the silica surface. ${ }^{33}$ Therefore, in this paper, an effort is made to detect the ethanol released during the sol-gel reaction in the rubber matrix and to give an estimate for its amount as being crucial for the industrial scale of manufacturing of in situ rubber-silica nanocomposites. Moreover, there is a general lack of information regarding the chemical structure of the obtained silica produced via the solgel reaction and consequently little or no understanding of the interface nature or the interactions between the formed silica particle and the rubber matrix. The bound rubber content is commonly used as an indirect measure for the magnitude of these rubber-silica interactions, simply because this parameter is directly related to the surface chemistry of the filler. ${ }^{34}$ The importance of the specific silica surface was also illustrated by various modification studies ${ }^{35,36}$ conducted to provide a silica structure with a more hydrophobic surface, resulting in enhanced rubber-silica interactions, and thereby improved compatibility with the rubber matrix. Thus, in this paper we attempt to provide a better understanding of the silica structure as prepared via sol-gel reaction inside a rubber matrix, including the amount of ethanol released and the silica surface and bulk interactions with the rubber matrix.

\section{EXPERIMENTAL SECTION}

Materials. Tetraethyl orthosilicate (TEOS) and $n$-hexylamine (as catalyst) were purchased from Aldrich and used as received. The highly dispersible (HD) silica is used for conventional mixing under the name Zeosil 1165 MP produced by Rhodia, commonly used in the rubber industry for the production of "green" tires. It has a BET surface area of $150 \mathrm{~m}^{2} / \mathrm{g}$ and an average particle size of $10-20 \mathrm{~nm}$.

The characteristics of the two rubbers, namely natural rubber (NR; Tun Abdul Razak Research Centre) and ethylene-propylene diene rubber (EPDM; LANXESS), are summarized in Table 1. It should be

Table 1. Characteristics of Rubber Materials Used

\begin{tabular}{lll}
\multicolumn{1}{c}{ rubber type } & \multicolumn{1}{c}{ NR SMR L } & \multicolumn{1}{c}{ EPDM Keltan 512 } \\
composition [wt \%] & $\begin{array}{c}\text { isoprene }(1,4- \\
\text { cis })\end{array}$ & $\begin{array}{c}\text { ethylene/propylene/ENB } \\
55 / 41 / 4.3\end{array}$ \\
impurity [wt \%] & 0.5 & \\
$M_{\mathrm{w}}[\mathrm{kg} / \mathrm{mol}]$ & $\sim 800$ & 260 \\
$\begin{array}{c}\text { Mooney viscosity ML } \\
(1+4)\end{array}$ & $50-60$ & $46\left(125^{\circ} \mathrm{C}\right)$ \\
$T_{\mathrm{g}}\left[{ }^{\circ} \mathrm{C}\right]$ & -65 & -54 \\
\hline
\end{tabular}

mentioned that it was difficult to determine the exact molecular weight of the NR sample via gel permeation chromatography due to the presence of residual gel. The literature ${ }^{37}$ suggests an approximate value for $M_{\mathrm{w}}$ of NR of $800 \mathrm{~kg} / \mathrm{mol}$ and $M_{\mathrm{w}} / M_{\mathrm{n}}=2.3$.

One must note that the used NR and EPDM rubbers were not chemically cross-linked; hence, no vulcanization process has been conducted. The rubbers were used as received, containing only physical network but no chemical connections between the chains. The reason the rubber was not chemically cross-linked is that from literature $^{38}$ is known that the cross-link density can influence the final particle size of the sol-gel synthesized silica.

Preparation of in Situ EPDM and NR Nanocomposites. The in situ rubber-silica nanocomposites were prepared as described by Ikeda et al. ${ }^{39}$ Nonvulcanized compression molded rubber sheets with dimensions of $10 \times 10 \times 1.5 \mathrm{~mm}^{3}$ were swollen in TEOS and then immersed in an aqueous hexylamine solution with a hexylamine concentration of $0.096 \mathrm{~mol} / \mathrm{L}$, using a constant weight ratio of $\mathrm{H}_{2} \mathrm{O}$ :TEOS $(5: 1 \mathrm{w} / \mathrm{w})$. After swelling the rubber matrix in TEOS, the sol-gel reaction proceeded at $80{ }^{\circ} \mathrm{C}$. The hexylamine catalyst gradually hydrolyzes the TEOS leading to formation of silica nanoparticles in the rubber matrix that resulted in in situ NR and EPDM nanocomposites with $\sim 10$ wt \% of silica, respectively. The amount of silica in wt \% can be controlled by varying the degree of swelling with the TEOS and the reaction time, as summarized in Table 2. The resulting in situ rubber-silica nanocomposites were dried for 72 $\mathrm{h}$ at $50{ }^{\circ} \mathrm{C}$ under vacuum.

Table 2. Preparation of in Situ NR and EPDM Nanocomposites with 10 wt \% Silica at $80{ }^{\circ} \mathrm{C}$

\begin{tabular}{lcc}
\hline type & TEOS amount [wt \%] & reaction time [min] \\
in situ NR nanocomposite & 50 & 60 \\
in situ EPDM nanocomposite & 33 & 600
\end{tabular}

Preparation of Sol-Gel Synthesized ex Situ Silica Powder. A sample of pure silica powder was prepared via the sol-gel reaction to allow study of the surface chemistry via solid-state NMR, XPS, and FTIR-TGA-MS. The sol-gel synthesized ex situ silica powder was prepared in the same way as the in situ rubber-silica nanocomposites, retaining the 5:1 weight ratio of $\mathrm{H}_{2} \mathrm{O}$ :TEOS. In absence of rubber, 50 $\mathrm{mL}$ of TEOS was mixed with $250 \mathrm{~mL}$ of aqueous solution of hexylamine $(0.096 \mathrm{~mol} / \mathrm{L})$, and the sol-gel reaction was performed under intense magnet stirring for $2 \mathrm{~h}$ at $40^{\circ} \mathrm{C}$. At the beginning of the reaction the mixture was transparent and thereafter turned milky. After $2 \mathrm{~h}$ reaction time the mixture was allowed to evaporate overnight in a fume hood and subsequently dried in an oven at $50{ }^{\circ} \mathrm{C}$ under vacuum for $72 \mathrm{~h}$. The dried silica powder was additionally heated for $48 \mathrm{~h}$ at $110^{\circ} \mathrm{C}$ under vacuum and nitrogen flow to remove any residual water or ethanol. A fine fluffy, clear white powder was obtained with BET measured surface area of $336 \mathrm{~m}^{2} / \mathrm{g}$ and average particle size in a range 
of 40-100 nm. The exchange of protons with deuterons for the HD silica and sol-gel synthesized samples was obtained by stirring the compounds in $\mathrm{D}_{2} \mathrm{O}$ overnight followed by drying under vacuum at 120 ${ }^{\circ} \mathrm{C}$.

Nuclear Magnetic Resonance (NMR). To study the chemical structure of the rubber-silica nanocomposites, single-pulse ${ }^{1} \mathrm{H}$ magicangle spinning (MAS) NMR spectra were recorded on a Bruker AVANCE I 700 spectrometer operating at a Larmor frequency of $700.25 \mathrm{MHz}$ for ${ }^{1} \mathrm{H}$. These experiments employed a $2.5 \mathrm{~mm}$ doubleresonance ${ }^{1} \mathrm{H}-\mathrm{X}$ MAS probe (Bruker) and a spinning frequency of 25.0 kHz. Both single-pulse ${ }^{29} \mathrm{Si}$ and ${ }^{29} \mathrm{Si}\left\{{ }^{1} \mathrm{H}\right\}$ cross-polarization/magicangle spinning ${ }^{40}$ (CP/MAS) experiments were carried out on a Bruker AVANCE I 700 spectrometer with a Larmor frequency of $139.12 \mathrm{MHz}$ for ${ }^{29} \mathrm{Si}$. These experiments used a $4.0 \mathrm{~mm}$ double-resonance ${ }^{1} \mathrm{H}-\mathrm{X}$ MAS probe with a MAS frequency of $10.0 \mathrm{kHz}$ and proton decoupling (TPPM) during acquisition. ${ }^{41}$ These experiments used a radio frequency of $50.0 \mathrm{kHz}$ corresponding to a $5.0 \mu \mathrm{s} 90^{\circ}$ pulse. For the single-pulse ${ }^{29} \mathrm{Si}$ MAS NMR spectra a flip angle of $\sim 30^{\circ}$ was employed together with a relaxation delay of $30 \mathrm{~s}$. The ${ }^{29} \mathrm{Si}\left\{{ }^{1} \mathrm{H}\right\} \mathrm{CP} / \mathrm{MAS}$ NMR measurements used a relaxation delay of $1.5 \mathrm{~s}$ and a $\mathrm{CP}$ contact time of $4.0 \mathrm{~ms}$. In the $2 \mathrm{D}{ }^{29} \mathrm{Si}\left\{{ }^{1} \mathrm{H}\right\}$ heteronuclear correlation (HETCOR) experiments, the indirect dimension was sampled in 128 steps using a $t_{1}$ dwell time of $30.0 \mu \mathrm{s}$. The $2 \mathrm{D}{ }^{13} \mathrm{C}\left\{{ }^{1} \mathrm{H}\right\}$ HETCOR spectrum was recorded on the Bruker AVANCE I 700 spectrometer-the same NMR spectrometer with a resonance frequency of $176.08 \mathrm{MHz}$ for ${ }^{13} \mathrm{C}$ in a $4.0 \mathrm{~mm}$ probe. A MAS frequency of $5.0 \mathrm{kHz}$ and ${ }^{1} \mathrm{H}$ TPPM decoupling during acquisition were applied. A relaxation delay of $3 \mathrm{~s}$ was used, and the indirect dimension had 64 steps for a $t_{1}$ dwell time of $50.0 \mu$ s and a CP contact time of $3.0 \mathrm{~ms}$. The ${ }^{15} \mathrm{~N}\left\{{ }^{1} \mathrm{H}\right\} \mathrm{CP} / \mathrm{MAS}$ NMR experiment was performed on a Bruker Avance I 300 spectrometer operating at a ${ }^{15} \mathrm{~N}$ Larmor frequency of 30.43 and $300.23 \mathrm{MHz}$ for ${ }^{1} \mathrm{H}$. A relaxation time of $3 \mathrm{~s}, 5.0 \mathrm{kHz}$ MAS, ${ }^{1} \mathrm{H}$ TPPM decoupling, and a CP contact time of $5.0 \mathrm{~ms}$ were used. The $2 \mathrm{D}$ ${ }^{13} \mathrm{C}\left\{{ }^{1} \mathrm{H}\right\}$ wide-line separation (WISE) ${ }^{42}$ NMR experiment was also carried out on the on a Bruker Avance I 300 spectrometer with a Larmor frequency of $75.49 \mathrm{MHz}$ for ${ }^{13} \mathrm{C}$. The spectrum was recorded at $4.0 \mathrm{kHz}$ MAS using a $7.0 \mathrm{~mm}$ double-resonance ${ }^{1} \mathrm{H}-\mathrm{X}$ probe with a $\mathrm{CP}$ contact time of $3.0 \mathrm{~ms}$. To prevent spinning side bands (ssbs) in the ${ }^{13} \mathrm{C}$ dimension, the total suppression of spinning sidebands (TOSS) technique was applied. ${ }^{43}$ Chemical shifts for ${ }^{1} \mathrm{H}$ and ${ }^{13} \mathrm{C}$ are reported in ppm relative to TMS using solid adamantane $\left(\delta_{\text {iso }}=1.85\right.$ ppm for ${ }^{1} \mathrm{H}, \delta_{\text {iso }}=38.484$ for ${ }^{13} \mathrm{C}$ ) as an external reference. ${ }^{44,45}$ The chemical shift of ${ }^{15} \mathrm{~N}$ was referenced to the ammonium site of $\mathrm{NH}_{4} \mathrm{NO}_{3}$ at $-358.4 \mathrm{ppm} .{ }^{46}$ The deconvolution of ${ }^{29} \mathrm{Si}$ MAS NMR spectra was performed using MATLAB by taking into account the resonance positions and their Gaussian/Lorentzian line widths as described by a pseudo-Voigt function. The final integration used the spectral edges as limits.

X-ray Photoelectron Spectroscopy (XPS). XPS is a surface analysis method that provides information for the chemical composition of the material surface based on the obtained binding energies. The measurements were carried out with a Thermo Scientific K-Alpha, equipped with a monochromatic small-spot X-ray source and a $180^{\circ}$ double focusing hemispherical analyzer with a 128-channel detector. Spectra were obtained using an aluminum anode ( $\mathrm{Al} \mathrm{K} \alpha=$ $1486.6 \mathrm{eV}$ ) operating at $72 \mathrm{~W}$ and a spot size of $400 \mu \mathrm{m}$. Survey scans were measured at a constant pass energy of $200 \mathrm{eV}$. The background pressure was $2 \times 10^{-9} \mathrm{mbar}$, and during measurement $4 \times 10^{-7} \mathrm{mbar}$ of argon was used for the charge compensation as dual beam source. The low-energy ions generated cause no sample damage but compensate for charging, preventing a shift in peak values that possibly could result in incorrect assignment of the peaks.

Transmission Electron Microscopy (TEM). The morphology of the nanocomposites was studied using TEM. Ultrathin sections (70$100 \mathrm{~nm}$ ) were obtained using a Reichert-Jung Ultracut E microtome equipped with a diatome diamond knife for dry trimming $\left(45^{\circ}\right.$ angle) and sectioning $\left(35^{\circ}\right.$ angle $)$ at a temperature of $-140{ }^{\circ} \mathrm{C}$. The sections were placed on a 200 mesh copper grid with a carbon supportive layer and examined with a Sphera electron microscope, FEI Tecnai 20 operated at $200 \mathrm{kV}$.
Bound Rubber Determination. The bound rubber content was estimated by immersing the rubber/silica nanocomposites with various silica amounts in THF. The ratio between the rubber/silica nanocomposites and the solvent was kept constant $(2 \% \mathrm{w} / \mathrm{v})$ and the samples were immersed in the solvent for $48 \mathrm{~h}$ at room temperature while shaking. The residues were dried for $72 \mathrm{~h}$ at $50{ }^{\circ} \mathrm{C}$ under vacuum. The bound rubber content was calculated using

$$
\text { wt } \% \text { bound rubber content }=\frac{W_{\text {residue }}-W_{\text {silica }}}{W_{\text {original }}-W_{\text {silica }}} \times 100
$$

where $W_{\text {residue }}(\mathrm{g})$ is the weight of the sample after solvent treatment, $W_{\text {original }}(\mathrm{g})$ is the weight of sample before solvent treatment, and $W_{\text {silica }}$ (g) is the weight of silica in the nanocomposite.

Thermogravimetric Analysis-Infrared Spectroscopy-Mass Spectroscopy (TGA-FTIR-MS). TGA-FTIR-MS measurements were performed at the Materia Nova Institute in Mons, Belgium. The purpose of the measurements was to determine the organic components, including the ethanol released from the sol-gel synthesized silica at a particular temperature. The thermogravimetric analyses were performed on a TGA Q5000 from TA Instruments using nitrogen as purge gas. The analysis of the evolved gases during the thermal degradation was carried out with a Bruker Tensor 27 FTIR spectrometer. Spectra were recorded $\left(4000\right.$ to $\left.600 \mathrm{~cm}^{-1}\right)$ using a gas cell heated at $225{ }^{\circ} \mathrm{C}$ and a mercury cadmium telluride (MCT) detector. The evolved gases were also analyzed by mass spectrometry on a Thermostar quadrupolar apparatus from Balzers Instruments covering a mass range from 0 to $300 \mathrm{amu}$. Evolved gases were ionized by electron impact $(70 \mathrm{eV})$. The simultaneous analysis of the gases by FTIR and MS spectrometers was made possible by a double coupling device. It consists of a Teflon-coated stainless steel " $T$ " connection which was heated at $225{ }^{\circ} \mathrm{C}$, thus avoiding any condensation of evolved gases. To this connection the mass spectrometer is connected via a $1 \mathrm{~m}$ long quartz capillary (i.d. $150 \mu \mathrm{m}$ ) heated at $200{ }^{\circ} \mathrm{C}$, while the gas cell of the FTIR spectrometer is connected through a $1 \mathrm{~m}$ long stainless steel tube (i.d. $2 \mathrm{~mm})$ heated at $225{ }^{\circ} \mathrm{C}\left(\mathrm{N}_{2}\right.$ flow of $25 \mathrm{~mL} /$ min, heating rate $20^{\circ} \mathrm{C} / \mathrm{min}$ ).

\section{RESULTS AND DISCUSSION}

Silica Structure via Solid-State NMR. The structure of the silica particles formed within the in situ rubber-silica nanocomposites is of crucial importance from several points of view. First, it is indicative for the completion of the sol-gel reaction (full hydrolysis of TEOS with no residual ethoxy groups), and second, it determines the rubber-silica interaction and thereby the degree of rubber reinforcement. This triggered us to perform a detailed analysis of the chemical structure of sol-gel synthesized silica in comparison with commercially available, highly dispersible (HD) silica using solid state NMR. A $\mathrm{D}_{2} \mathrm{O}$ treatment was applied to both silicas to distinguish between isolated and exchangeable silanol groups $(\mathrm{SiOH})$ and $\mathrm{H}_{2} \mathrm{O}$ present on the surface or/and inside the silica particles. Such differences may be indicative for possible changes in hydrophobicity.

Figures $1 \mathrm{a}$ and $\mathrm{lb}$ display the single-pulse ${ }^{1} \mathrm{H}$ MAS NMR spectra of sol-gel synthesized and HD silica and (black lines), respectively, and their deuterated analogues (red lines). We note that the chemical exchange of protons with deuterons in both silica samples is a uniform process, where protons that are accessible at the surface and in the bulk may be exchanged. From a comparison of the two ${ }^{1} \mathrm{H}$ MAS NMR spectra (black and red) in Figure 1a it is evident that the protons at $1.9 \mathrm{ppm}$ from $\mathrm{OH}$ groups at the surface can be exchanged by deuterons, showing a lower intensity peak. Bulk $\mathrm{OH}$ (hydrogen-bonded silanol groups) and silanol groups $\left(\mathrm{OH}\right.$ and $\left.(\mathrm{OH})_{2}\right)$ trapped inside the silica structure, resonating at the positions indicated in Figure 1a, do not show any changes in peak intensity after 

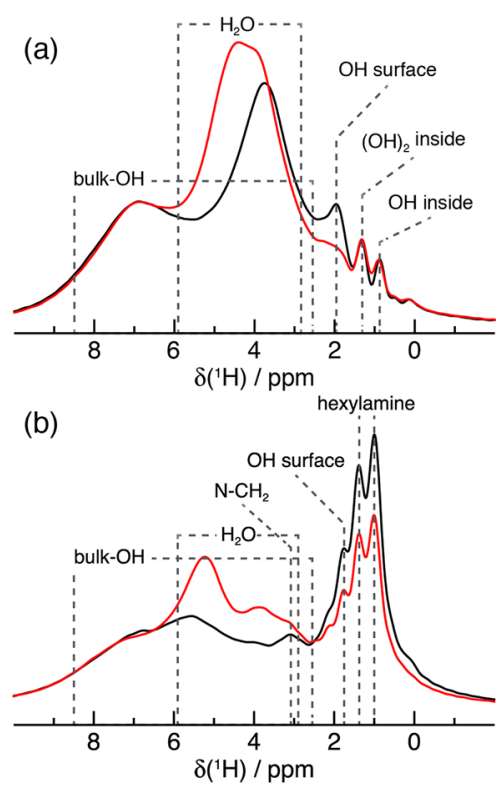

Figure 1. Single-pulse ${ }^{1} \mathrm{H}$ MAS NMR spectra recorded at a spinning frequency of $25.0 \mathrm{kHz}$ of (a) HD silica and (b) sol-gel synthesized silica. Both samples were dried at $120{ }^{\circ} \mathrm{C}$ under vacuum. The ${ }^{1} \mathrm{H}$ MAS NMR spectra in (a) and (b) are plotted on the same intensity scale taking into account the sample weights, respectively, where the spectra in black represent the samples as received/prepared and those in red after $\mathrm{D}_{2} \mathrm{O}$ exchange. The dashed lines mark the position and ranges of the different proton species as indicated.

exchange with the $\mathrm{D}_{2} \mathrm{O}$. Moreover, both the bulk $\mathrm{OH}$ and water signals do not occur as sharp, single resonances but are spread out over a ${ }^{1} \mathrm{H}$ chemical shift range of up to $6 \mathrm{ppm} .{ }^{47}$ For isolated $\mathrm{OH}$ groups at the surface, a ${ }^{1} \mathrm{H}$ chemical shift range between 1.8 and $2.0 \mathrm{ppm}$ has been reported, which is in good agreement with data presented in Figure 1a. ${ }^{47}$ We assign the additional proton signal at $1.1 \mathrm{ppm}$ to trapped, isolated $\mathrm{OH}$ groups inside the silica particles. ${ }^{4}$

The ${ }^{1} \mathrm{H}$ MAS NMR spectrum of sol-gel synthesized silica (Figure $1 \mathrm{~b}$ ) does not include well-resolved proton resonances from trapped $\mathrm{OH}$ and $(\mathrm{OH})_{2}$ groups, possibly due to the more intense hexylamine resonances that dominate the spectrum in that region. The signals assigned to the aliphatic tail of hexylamine show a significant intensity decrease after the $\mathrm{D}_{2} \mathrm{O}$ treatment, suggesting that hexylamine molecules adsorbed on the silica surface to some extent can be removed by washing with $\mathrm{D}_{2} \mathrm{O}$. Another interesting difference between the sol-gel synthesized silica and HD silica is the difference in the ratio between $\mathrm{H}_{2} \mathrm{O}$ and bulk $\mathrm{OH}$, resonating between 3.5-6.0 ppm and 6.0-9.0 ppm, respectively (dashed lines in Figure 1a,b). The lower relative intensity of the $\mathrm{H}_{2} \mathrm{O}$ peak observed for the sol-gel synthesized silica possibly originates from having fewer $\mathrm{OH}$ groups (i.e., a more hydrophobic surface) and therefore fewer physisorbed $\mathrm{H}_{2} \mathrm{O}$ at the surface.

To further characterize the differences in chemical structure for sol-gel synthesized and HD silica, we have used 2D ${ }^{29} \mathrm{Si}\left\{{ }^{1} \mathrm{H}\right\}$ heteronuclear correlation (HETCOR) NMR spectroscopy as summarized in Figure 2. Figure 2a shows a strong, intense correlation between $\mathrm{Q}^{3}$ silicon atoms and $\mathrm{OH}$ groups, which is also observed for $\mathrm{HD}$ silica in Figure $2 \mathrm{~b}$. This correlation provides clear evidence for the existence of $\mathrm{OH}$ groups at the silica surface (see Figure 2c). Interestingly, the remaining spectral features observed in the $2 \mathrm{D}{ }^{29} \mathrm{Si}\left\{{ }^{1} \mathrm{H}\right\}$
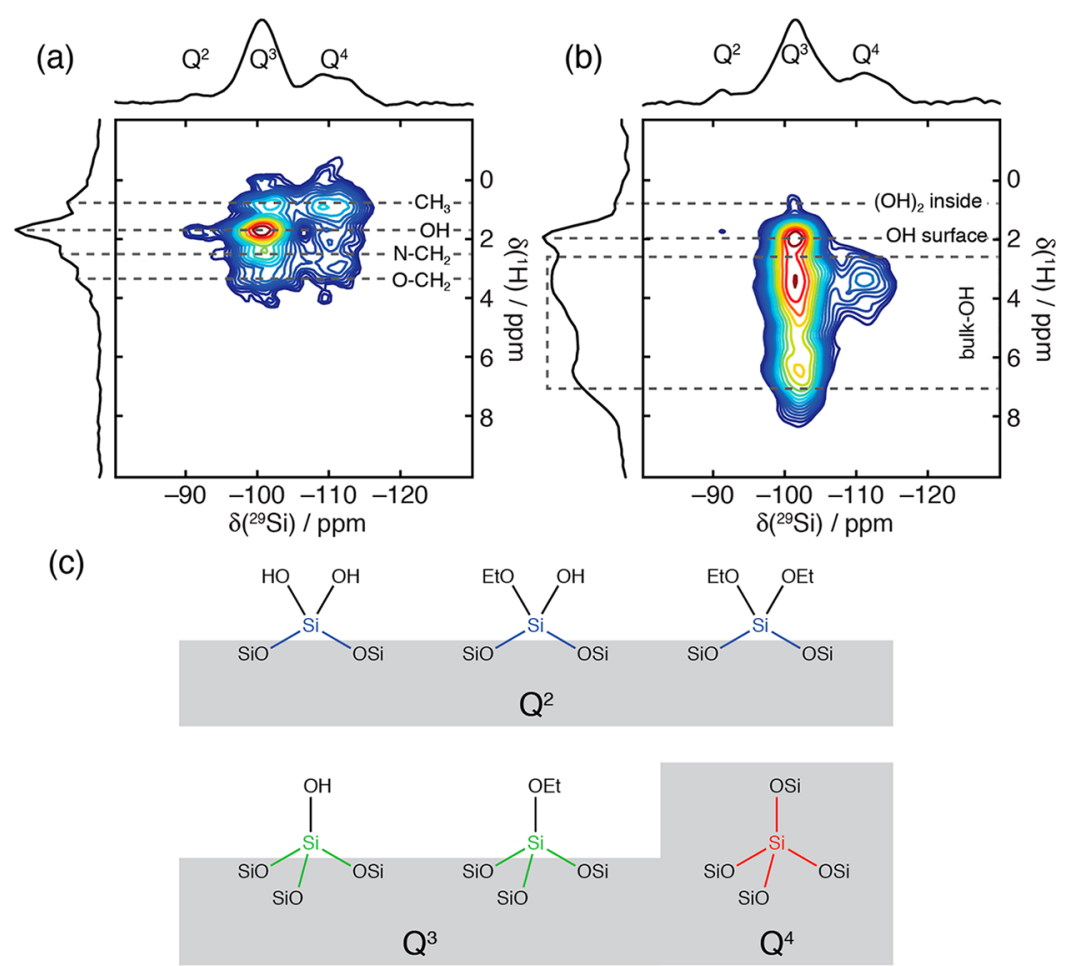

Figure 2. $2 \mathrm{D}^{29} \mathrm{Si}\left\{{ }^{1} \mathrm{H}\right\}$ HETCOR NMR spectra of (a) sol-gel synthesized silica and (b) HD silica recorded using a MAS frequency of $10.0 \mathrm{kHz}$ and a CP time of $4.0 \mathrm{~ms}$. (c) Schematic drawing of the possible silicon tetrahedra denoted as $\mathrm{Q}^{n}$, with $n=2,3,4$, corresponding to the number of $\mathrm{Si}-\mathrm{O}-$ Si bonds. $\mathrm{Q}^{2}$ corresponds to silicon atoms with two $\mathrm{Si}-\mathrm{O}-\mathrm{Si}$ bonds and two hydroxyl groups, two ethoxy groups, or hydroxyl and ethoxy group. $\mathrm{Q}^{3}$ is related to three $\mathrm{Si}-\mathrm{O}-\mathrm{Si}$ bonds and a connection to either one hydroxyl or one ethoxy group. $\mathrm{Q}^{4}$ corresponds to silicon atoms that only have siloxane bonds. The gray shading in (c) represents bulk silica corresponding to $\mathrm{Q}^{4}$ silicon atoms. 
HETCOR NMR spectra for sol-gel synthesized and HD silica are very different. In Figure $2 \mathrm{a}$, the $\mathrm{N}-\mathrm{CH}_{2}$ (hexylamine) resonates at proton chemical shift of $2.5 \mathrm{ppm}$ and the $\mathrm{CH}_{3}$ (methyl) at $0.8 \mathrm{ppm}$. The ethoxy groups show correlations to both $\mathrm{Q}^{3}$ and $\mathrm{Q}^{4}$ silicon atoms, indicating that their presence is not only at the surface but also in the bulk. The $2 \mathrm{D}$ correlation signals between the $\mathrm{N}-\mathrm{CH}_{2}$ group of hexylamine and the $\mathrm{Q}^{3}$ sites further indicate that the polar amine headgroup is only located at the surface of the silica nanoparticles. Moreover, bulk $\mathrm{OH}$ and hydrogen bonded $\mathrm{OH}$ groups, represented by a broad proton resonance at 3-8 ppm for HD silica, are not observed for sol-gel synthesized silica (cf. Figures $2 \mathrm{a}$ and $2 \mathrm{~b}$ ). A possible reason for this difference between the two silicas is that the ethoxy groups and hexylamine present at the silica surface shield the $\mathrm{OH}$ groups, preventing them from forming hydrogen bonds. To confirm the presence of hexylamine and ethoxy groups for sol-gel synthesized silica, we performed 2D ${ }^{13} \mathrm{C}\left\{{ }^{1} \mathrm{H}\right\}$ HETCOR measurements, the results of which are shown in Figure 3a. This spectrum primarily shows the
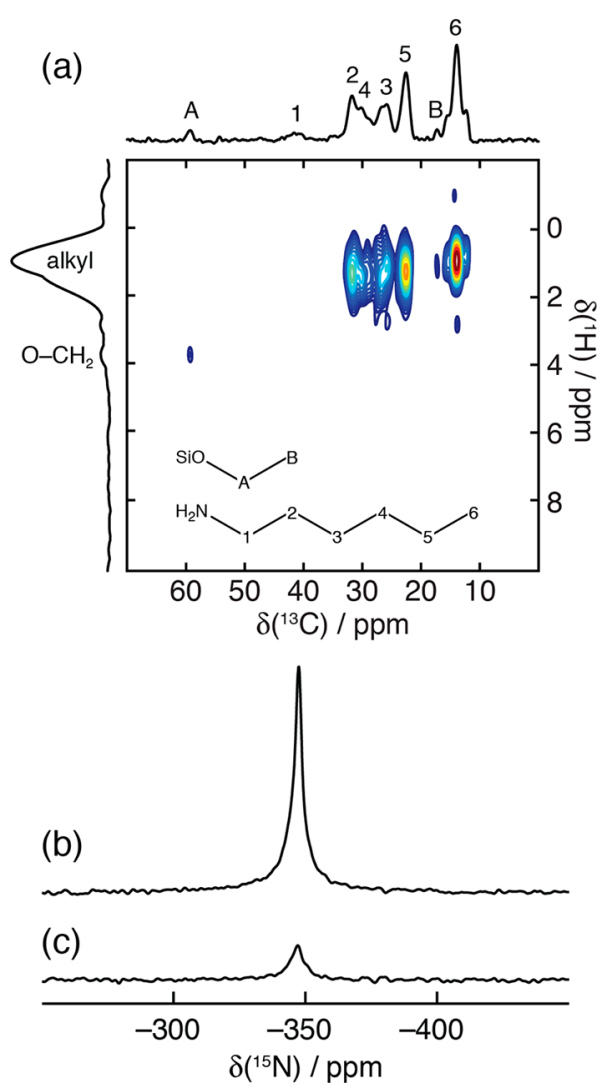

Figure 3. (a) $2 \mathrm{D}{ }^{13} \mathrm{C}\left\{{ }^{1} \mathrm{H}\right\}$ HETCOR NMR spectrum of sol-gel synthesized silica. $1 \mathrm{D}{ }^{15} \mathrm{~N}\left\{{ }^{1} \mathrm{H}\right\} \mathrm{CP} / \mathrm{MAS}$ NMR spectra of (b) sol-gel synthesized silica and (c) in situ NR nanocomposite. Both samples in (b) and (c) have employed ${ }^{15} \mathrm{~N}$-labeled hexylamine during the sol-gel reaction.

intramolecular correlations of the hexylamine (carbons 1-6) with their directly bonded alkyl protons. The correlation peaks originating from the ethoxy groups (denoted by A and B) are very weak, reflecting a low abundance of these groups. The presence of hexylamine in both sol-gel synthesized silica and the in situ synthesized NR nanocomposite is verified by the ${ }^{15} \mathrm{~N}\left\{{ }^{1} \mathrm{H}\right\} \mathrm{CP} / \mathrm{MAS}$ NMR spectra displayed in Figures $3 \mathrm{~b}$ and $3 \mathrm{c}$, which both include a single ${ }^{15} \mathrm{~N}$ resonance at $-347 \mathrm{ppm}$.
We note that for both of these samples ${ }^{15} \mathrm{~N}$-labeled hexylamine was used during the sol-gel reaction, since nitrogen has a very low abundance (0.37\%) and consequently a low NMR sensitivity. Thus, using ${ }^{15} \mathrm{~N}$-labeled hexylamine, we are able to confirm the presence of hexylamine in both sol-gel synthesized materials (Figure 3b,c). This result further demonstrates that the sol-gel synthesis and the inherent modification of the silica surface can be realized without additional chemical reactions and use of modifiers, highlighting its potential for industrial manufacturing processes and applications.

Additional evidence for the presence of hexylamine at the silica surface is provided via the $2 \mathrm{D}{ }^{13} \mathrm{C}\left\{{ }^{1} \mathrm{H}\right\}$ wideline separation (WISE) NMR spectrum shown in Figure 4, which

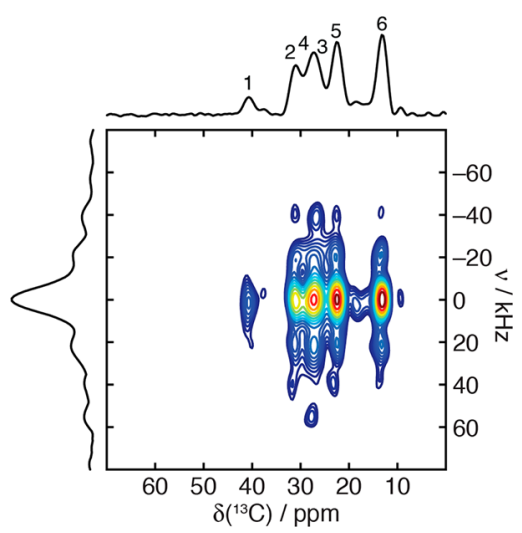

Figure 4. $2 \mathrm{D}^{13} \mathrm{C}\left\{{ }^{1} \mathrm{H}\right\}$ WISE NMR spectrum of hexylamine in sol-gel synthesized silica. The experiment was recorded at $7.05 \mathrm{~T}$ using a spinning frequency of $4.0 \mathrm{kHz}$ and a CP time of $3.0 \mathrm{~ms}$. The assignment scheme shown in Figure 3 has been used.

gives an estimation of the molecular flexibility. A rigid hexylamine (trapped inside the silica structure) would appear as a broad proton signal with a spectral width of up to $100 \mathrm{kHz}$ (vertical dimension), while a mobile hexylamine (free, nonbonded) would give rise to quite narrow proton lines. ${ }^{43}$ On the basis of the observed vertical width of $\sim 20-50 \mathrm{kHz}$ (Figure 4), we conclude that the hexylamine molecules are not trapped inside the silica nanoparticles, but more likely in the vicinity of the silica surface in an intermediate state, i.e., neither fully rigid nor fully mobile. ${ }^{42}$ It is expected the presence of hexylamine near the silica surface to contribute toward a more hydrophobic surface nature of the silica nanoparticles and improve its compatibility with the rubber, leading to improved mechanical properties of a rubber-silica nanocomposite.

The quality of the sol-gel synthesized and HD silicas can be determined from the ratio between $Q^{4}: Q^{3}: Q^{2}$ silicon atoms, and Figure 5 shows the quantitative single-pulse ${ }^{29} \mathrm{Si}$ MAS NMR spectra for HD silica, sol-gel synthesized silica, and the in situ NR nanocomposite. In general, all ${ }^{29} \mathrm{Si}$ MAS NMR spectra of Figure 5 include three different resonances at -91.7 , -101.4, and $-110.9 \mathrm{ppm}$, corresponding to $\mathrm{Q}^{2}, \mathrm{Q}^{3}$, and $\mathrm{Q}^{4}$ silicon tetrahedra, respectively. ${ }^{49,50}$ We note that it was difficult to distinguish the different types of silanol groups for the solgel synthesized silica from FTIR (data not shown). Instead, solid-state ${ }^{29} \mathrm{Si}$ MAS NMR provides a clear distinction and visualization of silicon tetrahedra bearing $\mathrm{OH}$ groups in addition to the silicon tetrahedra with residual (or nonhydrolyzed) ethoxy groups remnant from the TEOS precursor.

On the basis of the ${ }^{29} \mathrm{Si}$ MAS NMR spectra in Figure 5, we have performed a spectral deconvolution to determine the 


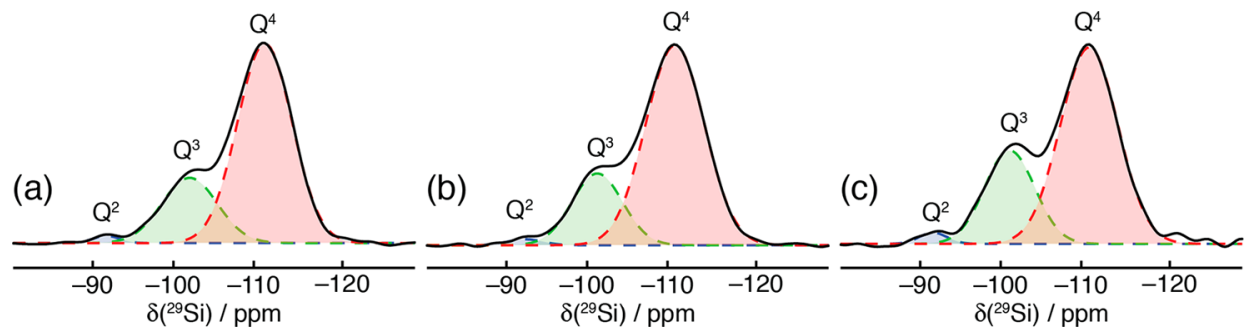

Figure 5. Quantitative single-pulse ${ }^{29} \mathrm{Si}$ MAS NMR spectra of (a) HD silica, (b) sol-gel synthesized silica, and (c) in situ NR nanocomposite. The dashed lines correspond to the deconvoluted signals.

intensities for $\mathrm{Q}^{2}, \mathrm{Q}^{3}$, and $\mathrm{Q}^{4}$, as illustrated in Figure 5 by the dashed lines. These show that the quality of the sol-gel synthesized silica as described by the $\mathrm{Q}^{4}: \mathrm{Q}^{3}: \mathrm{Q}^{2}$ ratio is $1.4(0.2): 23.9(1.1): 74.7(1.3)$, while this ratio for $\mathrm{HD}$ silica is $1.4(0.2): 23.2(1.1): 75.4(1.3)$. A slightly different ratio of $1.8(0.3): 30.0(1.2): 68.2(1.4)$ is obtained for the silica particles in the in situ NR nanocomposite. In this regard, the sol-gel synthesized silica has a structure that appears to be of very similar quality to that of HD silica. This can be ascribed to the confinement effect of the rubber on the growing silica particles resulting evidently in a somewhat lower degree of particle condensation. One must note that the silica particles formed in the in situ NR nanocomposite show a somewhat lower quality when compared to the sol-gel synthesized and the HD silica. This can be ascribed to the diffusion limitations of the reactants (TEOS and hexylamine) inside the rubber matrix, resulting evidently in a somewhat lower degree of particle condensation. Interestingly, since the $Q^{2}: Q^{3}$ ratios for sol-gel synthesized and $\mathrm{HD}$ silica are almost the same, and the only difference is that the sol-gel synthesized silica contains not only $\mathrm{Si}-\mathrm{OH}$ but also ethoxy $\left(\mathrm{Si}-\mathrm{OCH}_{2} \mathrm{CH}_{3}\right)$, one may assume that fewer $\mathrm{OH}$ groups are present in the sol-gel synthesized silica. This observation finally resolves a piece of the puzzle for the chemical structure of the sol-gel synthesized silica. Here, one may indeed conclude that not only the sol-gel synthesized silica nanoparticles do contain fewer $\mathrm{Si}-\mathrm{OH}$ groups, but in addition also residual ethoxy groups and hexylamine on or near the silica surface. These structural features contribute to the hydrophobic nature of the silica nanoparticles, regardless whether these are prepared $e x$ situ or inside a rubber matrix. Though the above results from solid-state NMR enable a detailed structure analysis of the different types of silica, it cannot provide easy access to information regarding the type of interactions existing between the silica nanoparticles and hexylamine and ethoxy residuals on or near the surface. Such phenomena become an issue when the stability of silica structure is addressed, and for this purpose we used X-ray photoelectron spectroscopy (XPS) to gain a better insight.

Mapping the Sol-Gel Synthesized Silica Surface Species by XPS. XPS is used for mapping the elemental composition of sol-gel synthesized silica in powder form and HD silica. The reason we did not use the silica particles formed directly in the rubber matrix is twofold. First, XPS only works for fine powders, and second, burning off the rubber at higher temperatures or treating it with an organic solvents is not desirable as it might affect the silica surface and lead to wrong conclusions. The chemical species from the analysis of the solgel synthesized and HD silica are summarized in Table 2. These data confirm the difference in the surface chemistry between the sol-gel synthesized and HD silica. The first difference originates from the total carbon content, which for sol-gel synthesized silica is $7.2 \%$ and $2.0 \%$ for HD silica. The higher carbon content for sol-gel synthesized silica can be ascribed to the presence of remnant ethoxy groups, hexylamine, and adsorbed carbon dioxide. The carbon content observed for HD silica can be only assigned to adsorbed carbon dioxide, as proven by the absence of a carbon XPS signal after removing a 10-15 nm layer from the surface of the HD silica with argon sputtering (data not shown).

Three types of carbon signals are included in Table 3 and assigned to $\mathrm{C}-\mathrm{C} / \mathrm{C}-\mathrm{H}, \mathrm{C}-\mathrm{O}$, and $\mathrm{C}=\mathrm{O}$ bonds appearing at

Table 3. XPS Results for Sol-Gel Synthesized and HD Silica

\begin{tabular}{|c|c|c|c|c|c|}
\hline \multirow[b]{2}{*}{$\begin{array}{l}\text { atomic } \\
\text { orbitals }\end{array}$} & \multicolumn{3}{|c|}{ sol-gel synthesized silica } & \multicolumn{2}{|c|}{ HD silica } \\
\hline & bond type & $\begin{array}{c}\text { binding } \\
\text { energy } \\
{[\mathrm{eV}]}\end{array}$ & $\begin{array}{c}\text { atomic } \\
\text { conc } \\
{[\%]}\end{array}$ & $\begin{array}{c}\text { binding } \\
\text { energy } \\
{[\mathrm{eV}]}\end{array}$ & $\begin{array}{c}\text { atomic } \\
\text { conc } \\
{[\%]}\end{array}$ \\
\hline $\mathrm{C}(1 \mathrm{~s})$ & $\mathrm{C}-\mathrm{C} / \mathrm{C}-\mathrm{H}$ & 284.4 & 5.36 & 284.8 & 1.33 \\
\hline$C(1 s)$ & $\mathrm{C}-\mathrm{O}$ & 285.8 & 1.42 & 286.2 & 0.5 \\
\hline $\mathrm{C}(1 \mathrm{~s})$ & $\mathrm{C}=\mathrm{O}$ & 287.3 & 0.35 & 287.7 & 0.16 \\
\hline $\mathrm{N}(1 \mathrm{~s})$ & $\mathrm{NH}_{2}$ (free) & 399.2 & 0.42 & 405.2 & 0 \\
\hline $\mathrm{N}(1 \mathrm{~s})$ & $\mathrm{NH}_{2}(\mathrm{HB})^{a}$ & 401.4 & 0.28 & 401.6 & 0 \\
\hline $\mathrm{Na}(1 \mathrm{~s})$ & $\mathrm{Na}$ & 1078.4 & 0 & 1072.7 & 0.37 \\
\hline $\mathrm{O}(1 \mathrm{~s})$ & $\mathrm{O}-(\mathrm{Si}, \mathrm{H}, \mathrm{C})$ & 532.6 & 64.4 & 532.6 & 68.5 \\
\hline $\operatorname{Si}(2 p)$ & $\mathrm{SiO}$ & 103.3 & 27.8 & 1.3.3 & 29.1 \\
\hline
\end{tabular}

284.4, 285.8, and 287.3 eV, respectively. Particularly, the higher concentration of the $\mathrm{C}-\mathrm{O}$ bond $(1.42 \%)$ for the sol-gel synthesized silica is consistent with the presence of ethoxy groups on the surface, although part of this signal can also originate from ethanol that is a byproduct of the sol-gel reaction. ${ }^{51}$ Moreover, the amino group of the hexylamine resulted in two characteristic signals: one at $401.4 \mathrm{eV}$ assigned to a hydrogen-bonded amine and another at $399.16 \mathrm{eV}$. Earlier studies suggested that the origin of the signal appearing at $399.16 \mathrm{eV}$ is due to either free amine $\mathrm{e}^{52}$ or chemisorbed amine forming a $\mathrm{Si}-\mathrm{N}$ bond. ${ }^{53,54}$ The TGA-FTIR-MS measurements performed in this work (see below) showed release of hexylamine at about $500{ }^{\circ} \mathrm{C}$, suggesting that it is more likely that chemisorbed amine is present rather than free amine at those temperature conditions. Moreover, since the sol-gel synthesized silica proceeds via an ionic mechanism, where hexylamine becomes protonated by accepting a proton from water, one expects to observe evidence for the ionic interactions between the positively charged hexylamine and possibly some remnant negatively charged silica entities situated at the silica surface. However, such ionic interactions should result in an additional amine signal located at $402.8 \mathrm{eV},{ }^{52}$ which in our case is not observed. The $\mathrm{O}(1 \mathrm{~s})$ binding energy for both the sol-gel synthesized and HD silica appears at $532.6 \mathrm{eV}$ and corresponds 

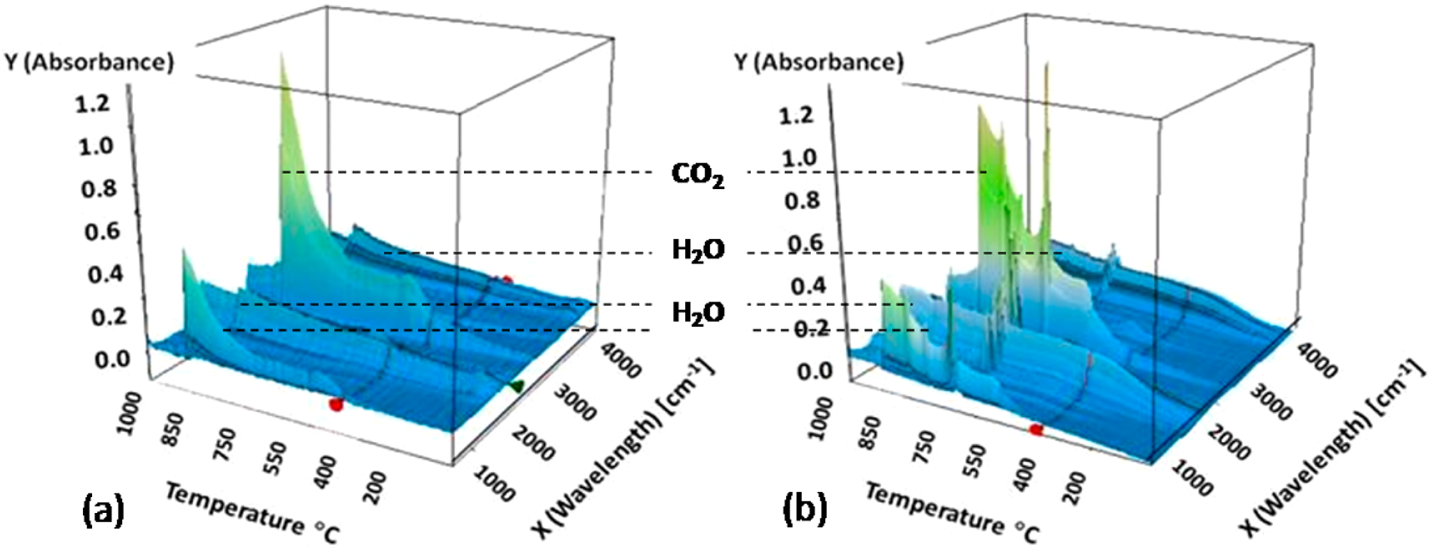

Figure 6. 3D time-resolved representation of a heat treatment of (a) HD and (b) sol-gel synthesized silica as followed by combinatory TGA-FTIRMS during heating until $1000^{\circ} \mathrm{C}$, employing a heating rate of $20^{\circ} \mathrm{C} / \mathrm{min}$.

to all bonded oxygen atoms $(\mathrm{O}-\mathrm{Si}, \mathrm{O}-\mathrm{H}$, and $\mathrm{O}-\mathrm{C})$, having very close binding energies and for this reason are difficult to distinguish. The $\mathrm{Si}(2 \mathrm{p})$ binding energy is $103.3 \mathrm{eV}$ and corresponds to $\mathrm{Si}-\mathrm{O}-\mathrm{Si}$ bonds. Thus, the XPS study shows that hexylamine is attached to the silica surface only via hydrogen bonding and chemisorption.

Time-Resolved Thermal Treatment of Sol-Gel Synthesized Silica via FTIR-TGA-MS. The physical and chemical changes of HD silica during a thermal treatment are reported in the literature ${ }^{1}$ while similar reports for sol-gel synthesized silica are still very limited. The purpose of using a combinatory TGA-FTIR-MS in this work is to be able to estimate whether ethanol is present inside the silica particles and to assess the way it is bonded to the silica surface (physical or chemical interactions) using the evaporation temperature as an indicator. It should be noted that a precise determination of the exact temperature at which one compound begins to evolve is difficult because there is always a certain delay between the evaporation of the compounds in the TGA instrument and their detection by the FTIR and the MS instruments. For this reason, when assigning a temperature, one must consider a narrow temperature region instead of a particular temperature. Spectra of the thermal treatment of sol-gel synthesized and HD silica using TGA-FTIR-MS are presented in Figure 6.

Figure 6 shows the evolution of chemical compounds at particular temperature regions during heating of $\mathrm{HD}$ and solgel synthesized silica. Both $3 \mathrm{D}$ representations show water peaks, mainly observed in the ranges of 1300-1800 and 3200$3800 \mathrm{~cm}^{-1}$, and the carbon dioxide $\left(\mathrm{CO}_{2}\right)$ peak at $2350 \mathrm{~cm}^{-1}$, all indicated with black dashed lines to guide the reader's eye. The extensive carbon dioxide evolution around $750{ }^{\circ} \mathrm{C}$ is assigned to the intensive decomposition of the organics evolving from the sol-gel synthesized silica at these high temperatures. The large peak of $\mathrm{CO}_{2}$ for sol-gel synthesized silica in the same temperature region is also observed in the $\mathrm{HD}$ spectra. The presence of adsorbed $\mathrm{CO}_{2}$ on the $\mathrm{HD}$ silica surface was earlier confirmed by XPS (see Table 3 ) expected to be removed already at lower temperatures, so the large $\mathrm{CO}_{2}$ peak appearing around $750{ }^{\circ} \mathrm{C}$ in $\mathrm{HD}$ silica can be ascribed to presence of degradation products. Moreover, the spectrum of the sol-gel synthesized silica in Figure $6 \mathrm{~b}$ contains other, smaller peaks appearing at various wavelengths, suggesting the evolution of other organics, besides water and $\mathrm{CO}_{2}$.

A more quantitative view of the chemical changes during the thermal treatment of the sol-gel synthesized and HD silica is given by the weight loss shown in Figure 7 . The total weight loss of the sol-gel synthesized silica (15.3\%), as calculated

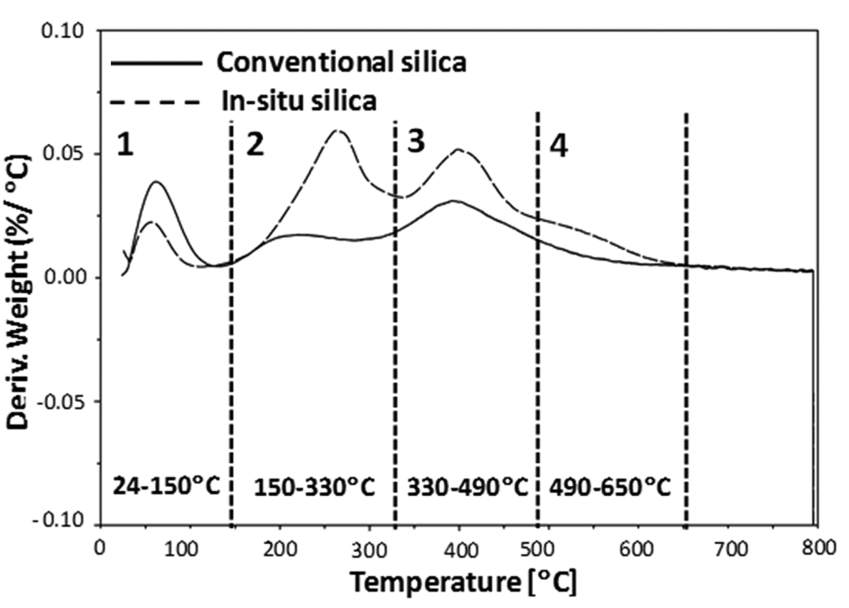

Figure 7. DTG thermograms of sol-gel synthesized and conventional silica obtained during thermal treatment up to $800{ }^{\circ} \mathrm{C}$.

from the TGA data, is higher than for the HD silica (9.5\%), indicating a higher concentration of organic compounds present.

In region $1\left(25-150{ }^{\circ} \mathrm{C}\right)$ of Figure 7 , weight losses are caused only by the removal of physical water from both materials. For sol-gel synthesized silica, FTIR and MS analysis confirmed that only water (no other organics) was removed in this temperature interval. Even though the two silica materials were dried under the same conditions, the sol-gel synthesized silica released less adsorbed physical water (1\%) than the HD silica $(2 \%)$, despite the significantly larger BET surface area, $336 \mathrm{~m}^{2} / \mathrm{g}$. We would expect silica with larger surface area to have higher absorbing capacity for moisture, hence more physically bounded water. However, as shown in the study so far, the sol-gel synthesized silica has a unique hydrophobic surface due to the presence of hexylamine and ethoxy groups that prevents additional absorption of physically bounded water despite the larger surface area. Therefore, the lower absorbed physical water (1\%) by the sol-gel synthesized silica can be clearly ascribed to the hydrophobic surface. One must consider that determining the "specific" surface area, hence considering the density of the silica, is very questionable. The sol-gel synthesized silica is expected to have lower density than $2.1 \mathrm{~g} /$ 

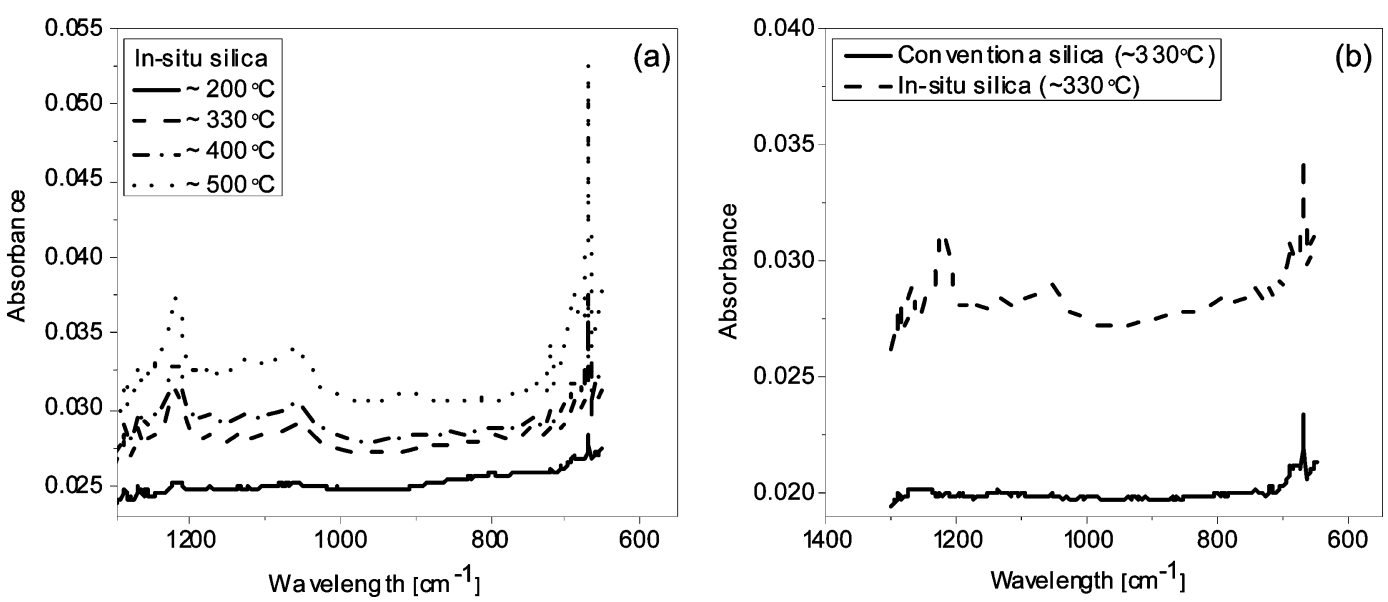

Figure 8. (a) FTIR spectra of sol-gel synthesized silica at different temperatures and (b) comparison of HD and sol-gel synthesized silica at approximately $330{ }^{\circ} \mathrm{C}$.

$\mathrm{cm}^{3}$ (HD), not fully completed condensation step during the sol-gel reaction, as it was shown from several density measurements (using a picnometer) that density ranges between 1.7 and $1.95 \mathrm{~g} / \mathrm{cm}^{3}$.

This points toward a more hydrophobic nature of the solgel synthesized silica due to the ethoxy groups and the hexylamine residing at or near the surface. In region 2 (150$330{ }^{\circ} \mathrm{C}$ ) and region $3\left(330-490^{\circ} \mathrm{C}\right)$, more intensive chemical changes occur in the sol-gel synthesized and $\mathrm{HD}$ silica, resulting in the release of chemically bonded water, rapid condensation of the silanol groups in both materials and, for the sol-gel synthesized silica, the additional release of organic components as indicated by the FTIR spectra shown in Figure 8.

In Figure 8a, the FTIR spectra of sol-gel synthesized silica suggests the presence of hexylamine $\left(1121 \mathrm{~cm}^{-1}\right)$ and ethanol $\left(1055 \mathrm{~cm}^{-1}\right)$ that begin to evolve at approximately $300{ }^{\circ} \mathrm{C}$. These observations indicate that both hexylamine and ethanol are bound to the silica surface via hydrogen bonds. As indicated by the XPS results (see Table 3), hexylamine is hydrogen bonded, and we expect ethanol also to be hydrogen bonded to the $\mathrm{OH}$ groups existing on the silica surface. As the absorption bands of a component can differ in its liquid and gaseous state, the absorption bands of hexylamine and ethanol were determined in their gas phase (FTIR-TGA), as shown in Table 4.

Table 4. FTIR Assignments of Pure Hexylamine, Ethanol, and TEOS in the Gas Phase As Determined with TGA-FTIR

$\begin{array}{ccc}\text { hexylamine }\left[\mathrm{cm}^{-1}\right] & \text { ethanol }\left[\mathrm{cm}^{-1}\right] & \text { TEOS }\left[\mathrm{cm}^{-1}\right] \\ 1124 & 1055 & 1393 \\ & 1408 & 1116 \\ 1242 & 961 \\ & 793\end{array}$

Another peak showing a similar trend with temperature as the two peaks from ethanol and hexylamine appears in the range $1220-1225 \mathrm{~cm}^{-1}$. This signal is difficult to assign because it does not correspond to any of the components shown in Table 4. Since it is close to the one of ethanol $\left(1242 \mathrm{~cm}^{-1}\right)$ and since MS does not suggest the presence of other relevant organics, we might assume that it originates from ethanol. The difference between sol-gel synthesized and HD silica at the same temperature conditions $\left(\sim 330^{\circ} \mathrm{C}\right)$ is clearly observed in Figure $8 \mathrm{~b}$, where HD silica does not reveal the presence of any organics, as indicated by the absence of peaks in the region $600-1400 \mathrm{~cm}^{-1}$, while the sol-gel synthesized silica clearly shows the presence of organics via three distinguished peaks.

Following the thermal treatment of sol-gel synthesized silica with the mass spectrometer part (MS) of the combinatory FTIR-TGA-MS equipment until $1000{ }^{\circ} \mathrm{C}$ revealed an additional interesting insight into the sol-gel synthesized silica, as shown in Figure 9.

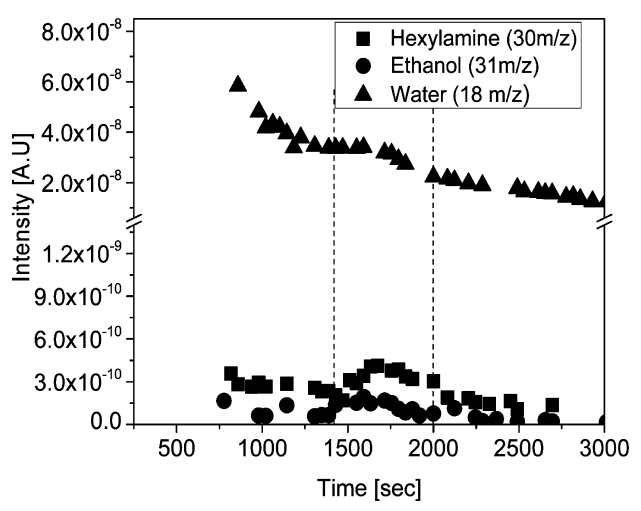

Figure 9. Hexylamine, ethanol, and water amounts as detected by MS during thermal treatment of sol-gel synthesized silica up to $1000{ }^{\circ} \mathrm{C}$ using a heating rate of $3{ }^{\circ} \mathrm{C} / \mathrm{s}$.

In Figure 9, hexylamine, ethanol, and water are followed by their ionization species with 30,31 , and 18 mass-to-charge ratios $(m / z)$, respectively, as a function of time and temperature. These ionized species were selected because these give the highest abundance in the MS spectra of their pure components. The results suggest a relatively low content of ethanol and hexylamine when compared to water. There are several reasons for the higher amount of water released throughout the thermal treatment: (i) condensation of silanol groups, (ii) strong hydrogen-bonded water on the outer surface or inner structure, (iii) water trapped in small micropores inside the particles and trapped water molecules in the sol-gel synthesized silica structure that can be released at high temperatures. Interestingly, in this temperature region (corresponding to region 4 in Figure 7 , indicated by the vertical 

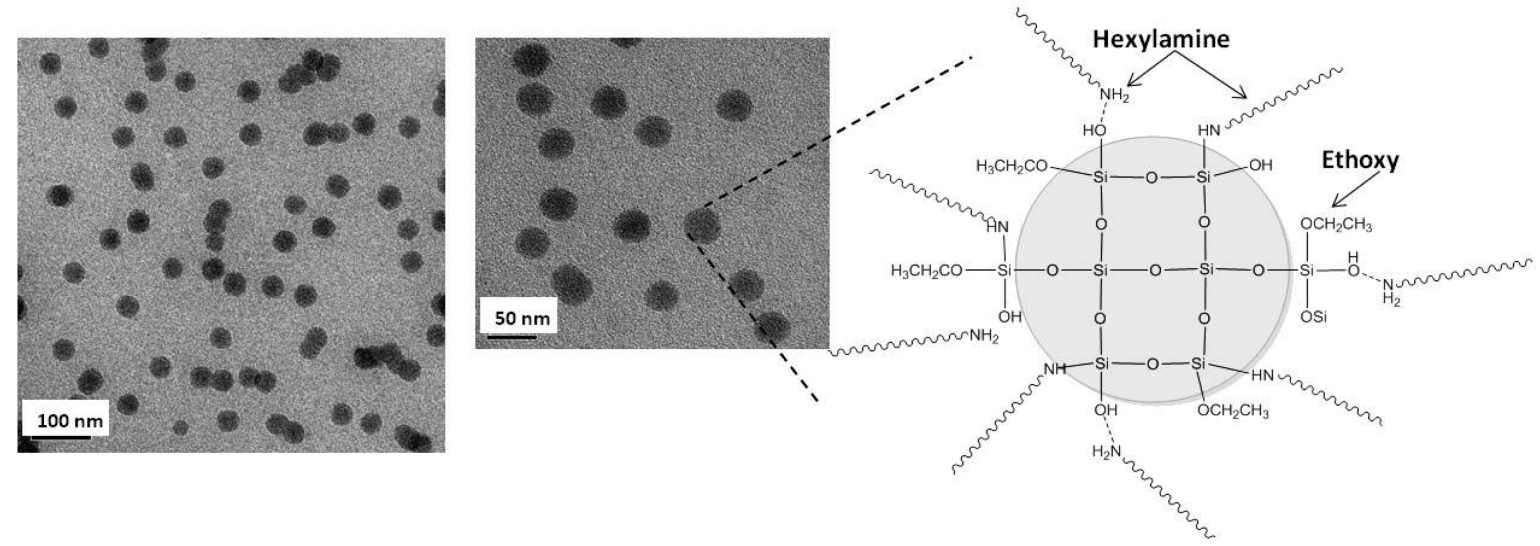

Figure 10. Representation of the morphology and chemical structure of the sol-gel synthesized silica in EPDM rubber matrix. An in situ EPDM nanocomposite containing $10 \mathrm{wt} \%$ sol-gel synthesized silica prepared as elaborated in the Experimental Section.

dashed lines, $490-650{ }^{\circ} \mathrm{C}$ ) a maximum for all three components (hexylamine, ethanol, and water) is observed. This maximum possibly originates from the postcondensation reaction occurring at this temperature that pushes the sol-gel reaction further toward completion, resulting in formation of additional ethanol and water. Moreover, one must not exclude the possibility that ethanol molecules might also be trapped inside the silica particles and released in this temperature range. It should be noted that the ethanol amount is surprisingly low. A possible reason could be that the hydrophobic surface on the sol-gel synthesized silica limits the number of ethanol molecules that can interact via hydrogen bonds with the Si$\mathrm{OH}$ groups. In addition, the presence of residual ethoxy groups inside the silica particles also creates an unfavorable environment for the ethanol to remain trapped during the sol-gel reaction. The temperature region of the observed maxima in Figure 9 corresponds well to the extensive evolution of $\mathrm{CO}_{2}$ in the same temperature range (see Figure $6 \mathrm{~b}$ ), which is related to intensive decomposition of the high amount of organics released.

To our surprise, residual nonreacted TEOS was not registered in the sol-gel synthesized silica powder, suggesting excellent conversion of the precursor into a solid silica particles and/or proper drying conditions.

Physical and Chemical Structure of Sol-Gel Synthesized Silica. The sol-gel synthesized silica is grown directly in the EPDM rubber matrix, uniformly distributed in the formed in situ EPDM nanocomposite with sizes ranging between 25 and $35 \mathrm{~nm}$, as shown in Figure 10. The size, shape, and particle density (number of particles in certain volume) of the sol-gel synthesized silica strongly depend on two general factors: the type of rubber matrix in which they are grown (EPDM, NR, SBR) and the reaction parameters (e.g., amount of TEOS, temperature, and reaction rate). The morphology of the obtained in situ nanocomposites as a function of the two main factors has been extensively discussed more in detail in our previous paper. ${ }^{55}$ In this paper we also showed existence of socalled gradient in particle size along the sample thickness due to diffusion limitations, where larger silica $(\sim 35 \mathrm{~nm})$ particles were formed closer to the surface and smaller $(\sim 16 \mathrm{~nm})$ toward the sample center. This is an important factor that might significantly influence the overall surface area of the solgel synthesized silica in the rubber matrix. One must consider the challenge involved in determining the surface area of the sol-gel synthesized silica which can be used either prepared in ex situ conditions or isolated from the rubber matrix by burning or dissolving the rubber. In the ex situ obtained sol-gel synthesized silica one must be aware of the size $(40-110 \mathrm{~nm})$, shape, and particle aggregation difference from the silica grown directly in the rubber (well-separated small size particles 20-35 $\mathrm{nm}$ ) or the consequences of burning or dissolving the rubber for isolating the sol-gel synthesized silica which can influence the surface of the silica and hence the surface area. Despite the prons and cons of both approaches, we decided to use the solgel synthesized silica prepared ex situ. The BET measurement showed surface area of $336 \mathrm{~m}^{2} / \mathrm{g}$, which is significantly larger when compared to the one of the HD silica $\left(150 \mathrm{~m}^{2} / \mathrm{g}\right)$. One possible explanation can be that the sol-gel synthesized silica particles are less aggregated due to the more hydrophobic surface, resulting in overall larger surface area unlike the strongly aggregated HD silica due to its hydrophilic surface. Regarding the chemical structure, in this study, we showed that is significantly different from the HD silica. Ethoxy groups have shown to be present inside the silica and on the silica surface, while hexylamine molecules reside mainly at the surface, in full agreement with the results of our previous study on the silica formation mechanism in rubber matrix via sol-gel reaction. ${ }^{49}$ In that study using the toluene model system and several characterization techniques, we showed that the silica formation in rubber matrix proceeds via an emulsion mechanism, where the hexylamine, being the catalyst, behaves also as surfactant. We revealed that hexylamine forms inverse micelles in the rubber matrix which act as nanoreactors hosting the sol-gel reaction for silica formation. In these inverse micelles the polar groups amino groups of the hexylamine are pointing toward the enclosed water in the center of the micelle, and the nonpolar aliphatic chains are facing the rubber phase. After solidification of the silica particles, the hexylamine (if not removed via calcination at $400{ }^{\circ} \mathrm{C}$ ) is expected to remain on the silica surface, resulting in silica particles with a more hydrophobic nature and consequently increased compatibility with the rubber matrix. This provides a unique chemical structure which resembles so-called "hairy" silica particles, as schematically presented in Figure 10.

These particles are called "hairy" due to the ethoxy groups and the long aliphatic chains of the hexylamine sticking out from the silica surface. One can imagine that, besides TEOS being an alkoxy precursor for silica formation in the sol-gel reaction, other precursors can also be used, such as propyl and butyl orthosilicate. These precursors have longer aliphatic tails 


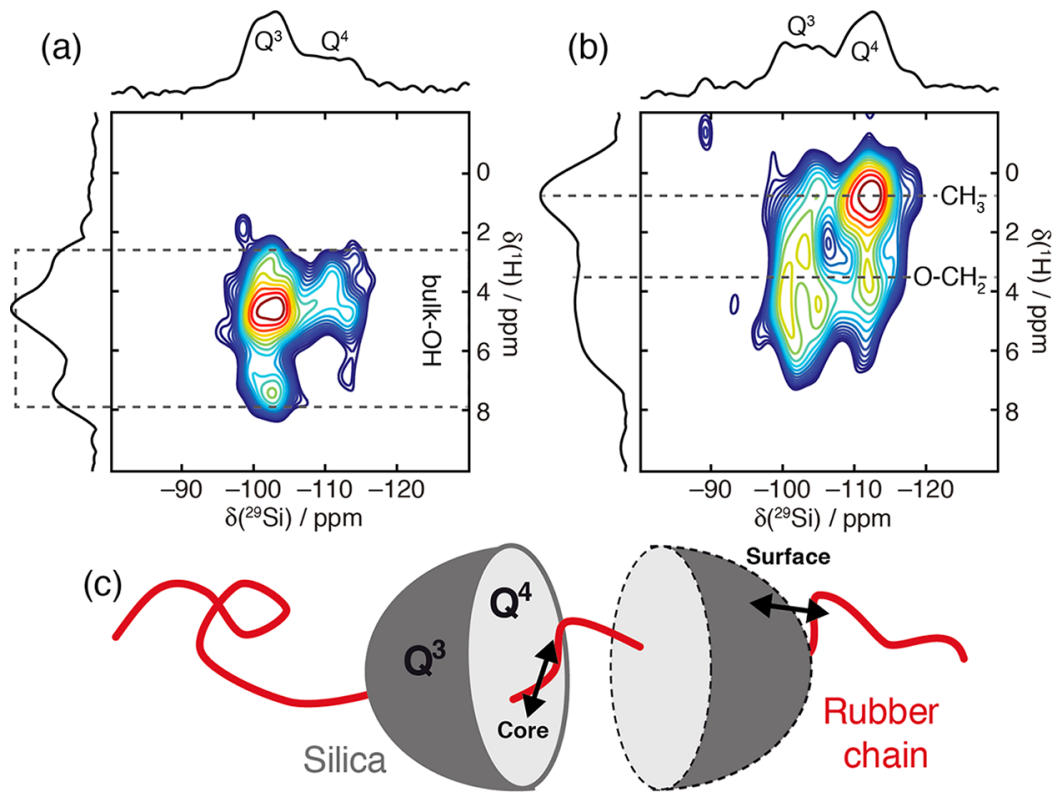

Figure 11. 2D ${ }^{29} \mathrm{Si}\left\{{ }^{1} \mathrm{H}\right\}$ HETCOR NMR spectra of (a) conventional EPDM and (b) in situ EPDM nanocomposite with $\sim 10$ wt \% silica. Both experiments were recorded using a MAS frequency of $10.0 \mathrm{kHz}$ and a CP time of $4.0 \mathrm{~ms}$. (c) Schematic representation of a trapped polymer chain inside sol-gel synthesized silica particle and its interactions with the core and surface as indicated by the black arrows.

that are expected to lead to even higher surface hairiness of the silica particles and consequently higher surface hydrophobicity and hence a better compatibility with the rubber matrix and potentially improved mechanical properties of in situ rubbersilica nanocomposites.

Entrapped Rubber Chains in Sol-Gel Synthesized Silica Particles. Considering that the silica nanoparticles are formed via a sol-gel reaction within the rubber matrix, it might be a possibility that these in situ rubber-silica nanocomposites have rubber chains trapped inside the sol-gel synthesized silica particles. To test this hypothesis, we have recorded $2 \mathrm{D}$ ${ }^{29} \mathrm{Si}\left\{{ }^{1} \mathrm{H}\right\}$ HETCOR NMR spectra for both the in situ EPDM and the conventional nanocomposite, as shown in Figure 11.

The 2D ${ }^{29} \mathrm{Si}\left\{{ }^{1} \mathrm{H}\right\}$ HETCOR NMR spectrum for the conventional composite shows the expected correlation between $\mathrm{Q}^{3}$ species and $\mathrm{OH}$ groups (Figure 11a), but for the in situ EPDM nanocomposite (Figure 11b), rather surprisingly, an intense correlation peak is present at $\sim 0.8 \mathrm{ppm}$ due to the interaction between $\mathrm{CH}_{3}$ groups and $\mathrm{Q}^{4}$ species. While the $\mathrm{CH}_{3}$ peak as such can be easily explained by the presence of ethoxy groups or hexylamine as observed in the $2 \mathrm{D}{ }^{29} \mathrm{Si}\left\{{ }^{1} \mathrm{H}\right\}$ HETCOR spectrum for the sol-gel synthesized silica (cf. Figures $2 \mathrm{a}$ and $11 \mathrm{~b}$ ), the only possible way for a $\mathrm{CH}_{3}$ group to correlate even more strongly with $\mathrm{Q}^{4}$ species, which is mainly present in the interior of the silica representing the $\mathrm{Si}-\mathrm{O}-\mathrm{Si}$ network, is that the $\mathrm{CH}_{3}$ group originates from the EPDM (the propylene unit) rubber itself (Figure 11c). This conclusion relies on the fact that all $2 \mathrm{D}{ }^{29} \mathrm{Si}\left\{{ }^{1} \mathrm{H}\right\}$ HETCOR experiments (Figures 2 and 11) were recorded using identical conditions. Moreover, our choice of a long CP time of $4.0 \mathrm{~ms}$ will also lead to an increase in the polarization transfer from ${ }^{1} \mathrm{H}$ to ${ }^{29} \mathrm{Si}$ for $\mathrm{Q}^{4}$ compared to $\mathrm{Q}^{3}$ with protons in their direct vicinity (see Figure 2c) due to the difference in CP kinetics for such groups. ${ }^{56}$ The absence of the $\mathrm{CH}_{3}$ peak in the EPDM conventional nanocomposite (Figure 11b) additionally contributes to our hypothesis of rubber chains entrapped inside silica particles. Obviously, entrapped chains can be, at least partially, responsible for the high bound rubber content of the in situ rubber-silica nanocomposites. The same correlation is also observed for the in situ NR nanocomposite (data not shown), which implies that this process may occur regardless of the rubber type. Thus, to the best of our knowledge, this work reports the first, and rather intriguing, evidence of entrapping polymer chains in growing sol-gel synthesized nanoparticles.

\section{CONCLUSIONS}

NR and EPDM rubber nanocomposites were prepared via an in situ sol-gel reaction using hexylamine as catalyst and TEOS as alkoxy precursor for the formation of silica particles directly in the rubber matrix. The chemical mapping of the silica particles was performed by solid-state NMR and XPS, revealing the presence of residual ethoxy groups and hexylamine on the silica surface. Ethoxy groups are present inside the silica structure as well as on the surface. Together with the hexylamine present at the surface, this results in an increase of hydrophobicity for the sol-gel synthesized formed silica particles as compared to silica particles in conventional rubber-silica nanocomposites. FTIRTGA-MS confirmed the higher amount of organic material present for the sol-gel synthesized silica as well as the low amount of ethanol present. The latter is important as the ethanol amount released is crucial for the industrial production of in situ rubber-silica nanocomposites. The chemical structure of sol-gel synthesized silica inside the rubber matrix, as well as ex situ prepared sol-gel synthesized silica via an aqueous solution of hexylamine, has comparable quality to that of commercial $\mathrm{HD}$ silica, as judged from the $\mathrm{Q}^{2}: \mathrm{Q}^{3}: \mathrm{Q}^{4}$ ratios determined using ${ }^{29} \mathrm{Si}$ MAS NMR measurements. The excellent dispersion of the sol-gel synthesized silica particles in the rubber matrix, their hydrophobic surface, and the entrapment of the rubber chains in the growing silica particles can be used as a scaffold for creating nanocomposites with improved mechanical properties as compared to conventional nanocomposites. 


\section{AUTHOR INFORMATION}

\section{Corresponding Authors}

*E-mail elena.miloskovska@sabic-ip.com (E.M.).

*E-mail mrh@chem.au.dk (M.R.H.).

Notes

The authors declare no competing financial interest.

\section{ACKNOWLEDGMENTS}

This research forms part of the research programme of the Dutch Polymer Institute (DPI), project \#652. Many thanks are to Anna Spoelstra (TU/e) for the TEM work, to the rubber group of Prof. Noordermeer and Prof. Dierkes (Twente University, Enschede, The Netherlands) for their fruitful discussions regarding the RPA results, and the DSM Elastomers team for performing part of the RPA measurements.

\section{REFERENCES}

(1) Iler, R. K. The Chemistry of Silica; Wiley-Interscience: New York, 1979

(2) Vansant, E. F.; Van Der Voort, P.; Vrancken, K. C. Characterization and Chemical Modification of the Silica Surface; Elsevier Science B.V.: Amsterdam, 1995.

(3) Brinker, J. C.; Scherer, G. W. The Physics and Chemistry of Sol-Gel Processing; Academic Press: London, 1990.

(4) Min Kim, J.; Mok Chang, S.; Min Kong, S.; Kim, K.; Kim, J.; Kim, W. Ceram. Int. 2009, 35, 1015-1019.

(5) Mihara, S. Reactive processing of silica-reinforced tire rubber.

$\mathrm{PhD}$ Thesis, Twente University, 2009.

(6) Sozzani, P.; Simonutti, R.; Comotti, A.; Bracco, S.; Simonelli, A. Chem. Mater. 2002, 34, 3377-3381.

(7) Sozzani, P.; Comotti, A.; Bracco, S.; Valsesia, P.; Ferretti, L. J. Am. Chem. Soc. 2007, 129, 8566-8576.

(8) Ibrahim, I. A. M.; Zikry, A. A. F.; Sharaf, M. A. J. Am. Sci. 2010, 6 (11), 985-989.

(9) Green, D. L.; Lin, J. S.; Lam, Y. F.; Hu, M. Z.; Schaefer, D. W.; Harris, M. T. J. Colloid Interface Sci. 2003, 266, 346-358.

(10) Blaaderen, A.; van Kentgens, A. P. M. J. Non-Cryst. Solids 1992, 149, 161-178.

(11) Bogush, G. H.; Tracy, M. A.; Zukoski, C. F. J. Non-Cryst. Solids 1988, 104, 95-106.

(12) Fröhlich, J.; Niedermeier, W.; Luginsland, H. D. Composites, Part A 2005, 36, 449-460.

(13) Sun, J.; Song, Y. H.; Zhang, Q. J. Polym. Sci., Part B 2007, 45, 2594-2602.

(14) Bokobza, L. Kautschuk Gummi Kunststoffe 2009, 62, 23-27.

(15) Frohlich, J.; Lugisland, H. D. Rubber World 2001, April 28.

(16) Brindha, M. E. Rubber World 2008, 239, 28-32.

(17) Merabia, S.; Sotta, P.; Didier, R. L. Macromolecules 2008, 41 (21), 8252-8266.

(18) Wrana, C.; Härtel, V. Kautschuk Gummi Kunststoffe 2008, 61, 647-655.

(19) Konecny, P.; Cerny, M.; Voldanova, J.; Malac, J.; Simonik, J. Polym. Adv. Technol. 2007, 18, 122-127.

(20) Poompradub, S.; Kohjiya, S.; Ikeda, Y. Chem. Lett. 2005, 34, $672-673$.

(21) Kohjiya, S.; Murakami, K.; Iio, S.; Tanahashi, T.; Ikeda, Y. Rubber Chem. Technol. 2001, 74, 16.

(22) Ansarifar, A.; Ibrahim, N.; Bennett, M. Rubber Chem. Technol. 2005, 78, 793-805.

(23) Ouyang, G. B. Kautschuk Gummi Kunststoffe 2006, 59, 332-343.

(24) Yatsuyanagi, F.; Kaidou, H.; Ito, M. Rubber Chem. Technol. 1999, 4, 657.

(25) Zhu, A. J.; Sternstein, S. S. Compos. Sci. Technol. 2003, 63, $1113-1126$.

(26) Sternstein, S. S.; Zhu, A. J. Macromolecules 2002, 35, 72627273
(27) Sozzani, P.; Simonutti, R.; Comotti, A.; Negroni, F. Chem. Mater. 1999, 11, 822-828.

(28) Leblanc, J. L. J. Appl. Polym. Sci. 2000, 78, 1541-1550.

(29) Joseph, R. Rubber World 2005, 232, 16-18.

(30) Ikeda, Y.; Kohjiya, S. J. Sol-Gel Sci. Technol. 2003, 26, 495-498.

(31) Bandyopadhyay, A.; Singha, N. K.; Bhowmick, A. K. J. Appl. Polym. Sci. 2005, 95, 1418-1422.

(32) Murakami, K.; Lio, S.; Ikeda, Y.; Kohjiya, S.; Tosaka, H. J. Mater. Sci. 2003, 38, 1447-1455.

(33) Dierkers, W. K. Economic Mixing of Silica-Rubber compounds. PhD Thesis, Twente University, 2005.

(34) Leblanc, J. L.; Hardy, P. Kautschuk Gummi Kunststoffe 1991, 44, 1119.

(35) Suratwala, M. L.; Hanna, E. L.; Miller, P. K.; Whitman, I. M.; Thomas, P. R. J. Non-Cryst. Solids 2003, 316, 349-363.

(36) Jal, P. K.; Patel, S.; Mishra, B. K. Talanta 2004, 62, 1005-1028.

(37) Rubber Engineering; Tata McGraw-Hill Company: New Delhi, 1998.

(38) Dasa, A.; Jurka, R.; Stöckelhuber, K. W.; Heinricha, G. J. Macromol. Sci., Part A: Pure Appl.Chem. 2007, 45, 101-106.

(39) Ikeda, Y.; Poompradub, S.; Morita, Y.; Kohjiya, S. J. Sol-Gel Sci. Technol. 2008, 48, 299-306.

(40) Pines, A.; Gibby, M.; Waugh, J. J. Chem. Phys. 1973, 59, 569.

(41) Bennett, A.; Rienstra, C.; Auger, M.; Lakshmi, K.; Griffin, R. J. Chem. Phys. 1995, 103, 6951.

(42) Schmidt-Rohr, K.; Clauss, J.; Spiess, H. W. Macromolecules 1992, $25,3273-3277$

(43) Schmidt-Rohr, K.; Spiess, H. W. Multidimensional Solid-State NMR and Polymers; Academic Press: New York, 1994.

(44) Hayashi, S.; Hayamizu, K. B. Chem. Soc. Jpn. 1991, 64, 685.

(45) Morcombe, C.; Zilm, K. J. Magn. Reson. 2003, 162, 479.

(46) Goward, G. R.; Schnell, I.; Brown, S. P.; Spiess, H. W.; Kim, H. D.; Ishida, H. Magn. Reson. Chem. 2001, 39, S5-S17.

(47) Maciel, G. E.; Charls, E.; Bronnimann, R.; Zeigler, C. J. Am. Chem. Soc. 1988, 110 (7), 2023-2026.

(48) D'espinose de la Caillerie, J.; Raouf Aimeur, M.; El Kortobi, Y.; Pierre Legrand, A. J. Colloid Interface Sci. 1997, 194 (2), 434-439.

(49) Maciel, G. E.; Kinney, D. R.; Chuang, I. J. Am. Chem. Soc. 1993, $115,6786-6794$.

(50) Maciel, G. E.; Changhua, C. L. J. Am. Chem. Soc. 1996, 118, 5103-5119.

(51) Miloskovska, E.; Hansen, M. R.; Friedrich, C.; HristovaBogaerds, D.; van Duin, M.; de With, G. Macromolecules 2014, 47, 5174.

(52) Kallury, K. M. R.; MacDonald, P. M.; Thompson, M. Langmuir 1994, 10, 492-499.

(53) Hamers, R. J.; Wietfeldt, J. R.; Wright, J. C. J. Phys. Chem. B 2001, 105, 3759-3768.

(54) Cao, X. P.; Hamers, R. J. J. Vac. Sci. Technol. 2002, 20 (4), 1614.

(55) Miloskovska, E.; Nies, E.; Hristova-Bogaerds, D.; van Duin, M.; de With, G. J. Polym. Sci., Part B: Polym. Phys. 2014, 52, 967-978.

(56) Kolodziejski, W.; Klinowski, J. Chem. Rev. 2002, 102, 613-628. 